\title{
Psicólogo na rede pública de educação: embates dentro e fora da própria profissão
}

\author{
Raquel Sousa Lobo Guzzo \\ Adinete Sousa da Costa Mezzalira \\ Ana Paula Gomes Moreira
}

\begin{abstract}
Resumo
O presente trabalho visou aprofundar um debate que vem crescendo dentre os psicólogos brasileiros a respeito da sua inserção nas políticas públicas educacionais. Em 2008, o Conselho Federal de Psicologia conduziu um amplo debate nacional sobre essa questão com os diferentes conselhos regionais. Os debates e as discussões resultantes desses encontros foram sistematizados e apresentados no Seminário Nacional do Ano da Educação em 2009. Com base nos relatórios apresentados, este estudo organiza o que foi registrado, focalizando a identificação de problemas e perspectivas necessárias à inserção do profissional nos processos de formular e avaliar as políticas educacionais, bem como de trabalhar no sistema público. Os registros foram organizados em três categorias: Psicologia Escolar e Educacional - formação e pesquisa em políticas públicas; Psicólogo escolar e educacional - inserção e participação nas políticas públicas educacionais; e Inserção do psicólogo no contexto público educacional - dilemas e perspectivas.
\end{abstract}

Palavras-chave: Psicologia Escolar, políticas públicas, formação profissional.

\section{Psychoogists in Public Education System: struggles in and outside their proffession}

\begin{abstract}
In this study we aim at deepening a debate that is growing among of Brazilian psychologists regarding their inclusion in educational public policies. In 2008 the Federal Council of Psychology led a wide national debate on this issue with the various regional councils. The debates and discussions arising from these meetings were organized and presented in National Seminar on Education of the Year in 2009. Based on reports, this study organizes what was registered focusing on the identification of problems and perspectives necessary for the insertion of professional in the process of formulating and evaluating the educational policies, as well as working at the public system. Thus, the broad categories found are: Educational and School Psychology: Training and research in public policy, school and educational psychologist: integration and participation in public policy education, and insertion of the psychologist in the public education: dilemmas and perspectives.
\end{abstract}

Keywords: School psychology, public policies, professional education.

\section{Psicólogo en la red pública de educación: enfrentamientos dentro y fuera de la profesión}

\begin{abstract}
Resumen
Este trabajo tuvo el objetivo de profundizar un debate que ha ido creciendo entre psicólogos brasileños: su inserción en las políticas públicas educacionales. En 2008 el Consejo Federal de Psicología condujo un amplio debate nacional sobre este tema con los diferentes consejos regionales. Los debates y discusiones resultantes de estos encuentros se sistematizaron y fueron presentados en el Seminario Nacional del Año de la Educación en 2009. Basado en los informes presentados este estudio organiza lo que se registró centrándose en la identificación de problemas y perspectivas necesarias a la inserción del profesional en los procesos de formulación y evaluación de las políticas educacionales, así como del trabajo en el sistema público. Los registros se organizaron en tres categorías: Psicología Escolar y Educacional - formación e investigación en políticas públicas; Psicólogo escolar y educacional - inserción y participación en políticas públicas educacionales; e Inserción del psicólogo en el contexto público educacional - dilemas y perspectivas.
\end{abstract}

Palabras Clave: Psicología Escolar; Políticas públicas educacionales; Formación profesional. 


\section{Introdução}

A presença do profissional de Psicologia na rede pública de educação brasileira é ainda uma utopia se considerarmos dois aspectos importantes: a quantidade de profissionais lotados nas secretarias de educação e as suas condições de inserção e atuação efetivas nesse campo. Apesar de alguns municípios brasileiros já possuírem profissionais contratados diretamente pelas Secretarias Municipais de Educação, é ainda um desafio a preparação e o desenvolvimento de práticas profissionais junto a crianças e adolescentes acompanhando in loco o processo de desenvolvimento nos espaços educativos.

A história dessa questão é reveladora dos inúmeros elementos determinantes, tanto dentro da própria área da Psicologia como de fora dela, que podem ser observadas nas pesquisas de Patto (1997, 2004), Guzzo, Martínez e Campos (2006), Marinho-Araujo (2010), dentre outras.

Para entendermos a complexidade dos embates com relação à inserção do psicólogo na rede pública de educação, é importante que destaquemos aqui, a partir de alguns estudos, uma caracterização sobre a situação do psicólogo e sua presença nas escolas. Alguns pesquisadores interessados nessa temática desenvolveram pesquisas que discutiam, dentre outros assuntos, a situação desse profissional na educação pública em alguns municípios do Brasil, como no caso das cidades de: Londrina - PR (Pandolfi e cols., 1999), Assis - SP (Cunha \& Betini, 2003), Vitória - ES (Rossetti, Silva, Batista, Stein, \& Hulle, 2004), Maceió - AL (Neves, 2007); Rio de Janeiro - RJ (Guedes, Aguiar, Rocha, \& Cunha, 2009), São Luís - MA (Carvalho \& Marinho-Araujo, 2009), Campina Grande - PB (Medeiros \& Aquino, 2011), bem como em Brasília - DF (Marinho-Araujo, Neves, Penna-Moreira, \& Barbosa, 2011).

Esses estudos apontam para diferentes elementos presentes nessa discussão ainda polêmica, mesmo entre profissionais da área. A certificação profissional obtida por um diploma generalista, após completar cinco anos de um curso de graduação, autoriza que o recém formado assuma postos de trabalho em qualquer contexto, sem que, necessariamente, tenha uma base teórica e prática que sustente sua inserção em campo. Para qualquer exercício prático, o profissional de Psicologia necessita apenas de um registro no Conselho Federal de Psicologia, não importando o tipo de preparação teórica e prática que obteve em sua formação básica, os estágios profissionalizantes que fez, ou mesmo que tipo de prática desenvolveu. Diante das pesquisas mencionadas anteriormente, arriscamos uma breve análise sobre a inserção do psicólogo nas Secretarias Municipais e Estaduais de Educação em nosso país.

No Paraná, a pesquisa realizada por Pandolfi e cols. (1999) revela que os psicólogos atuantes na rede pública de educação são profissionais transferidos, em sua grande maioria, da Secretaria de Saúde.
No Espírito Santo, de acordo com a investigação de Rossetti e cols. (2004), no ano 2001, a Lei Estadual no. 6.974, instituiu o serviço de Psicologia Escolar na rede pública de Ensino Fundamental e Médio, no entanto, até o ano de 2004 nenhum concurso público foi realizado em âmbito estadual para o cargo de psicólogo escolar.

$\mathrm{Na}$ cidade de Maceió e municípios adjacentes do estado de Alagoas, a pesquisadora Novaes (2007), ao investigar a realidade da Psicologia Escolar em 571 escolas, constatou que apenas 38 possuíam o serviço de Psicologia, distribuídas da seguinte forma: 33 em escolas particulares, três em escolas municipais, dois em escolas federais e nenhum nas escolas estaduais.

No município Rio de Janeiro, segundo Guedes e cols. (2009), no ano de 2007, a Prefeitura implantou a Rede de Proteção ao Educando - RPE, reunindo políticas de ações entre a Secretaria Municipal de Educação e da Assistência Social. A REP é composta por 104 psicólogos lotados na Secretaria Municipal de Educação, oriundos de concursos públicos da Secretaria Municipal de Saúde, portanto também remanejados.

Na cidade de São Luís do Maranhão, em 2008, a Secretaria Municipal de Educação realizou concurso público para psicólogo, oferecendo quatro vagas, sendo duas delas para psicólogo especialista em Psicopedagogia (Carvalho \& Marinho-Araujo, 2009). Nessa cidade, a exigência da especialidade em Psicopedagogia pode indicar a atuação realizada no campo educacional.

Na cidade de Campina Grande, Paraíba, Medeiros e Aquino (2011), ao investigarem a atuação de sete psicólogos de escolas públicas municipais, constataram que a maioria das profissionais possuía uma atuação na escola centrada no aluno. Com relação à especialidade das profissionais, duas são especialistas da Psicologia da Infância, duas em Psicopedagogia, uma em Gestão Educacional, uma em Psicologia da Personalidade e uma possui apenas a graduação. Mesmo tendo sido um estudo com foco em alguns psicólogos da rede municipal, o destaque que fazemos aqui é sobre a formação dos profissionais para o exercício de sua função.

No Distrito Federal, segundo Marinho-Araujo e cols. (2011), a primeira referência à Psicologia Escolar no âmbito educacional data de 1968, realizando atendimento psicopedagógico. Essa proposta de intervenção coadunava com a concepção biológico-evolucionista, predominante na Psicologia. A partir da década de 1990, houve vários avanços na Psicologia Escolar no sistema público de ensino no DF, ampliando a sua atuação para um trabalho institucional, interventivo e preventivo.

No ano de 2007, o Laboratório Interinstitucional de Estudos e Pesquisas em Psicologia Escolar (LIEPPE) do Instituto de Psicologia da Universidade de São Paulo investigou em âmbito nacional, sob a liderança de Souza, as concepções e práticas desenvolvidas pelos psicólogos da rede pública de ensino frente às queixas escolares. Participaram dessa pesquisa os seguintes estados: São Paulo, Minas Gerais, Rondônia, Santa Catarina, Acre, Paraná e Bahia. Os resultados foram publicados em diferentes relatos como o 
de Souza (2010), referente a São Paulo; os de Soares e Silva (2009) e Silva e Santos (2011) no que se refere a Minas Gerais; o de Tada, Sápia e Lima (2010) de Rondônia; os de Tondin, Dedonattie e Bonamigo (2010) e Tondin, Schott, Fiabini e Bonamigo (2011) de Santa Catarina; Tada (2011) no Acre; Viegas (2011) na Bahia; e, por fim, Facci, Barroco e Leal (2011) no Paraná.

No estado de São Paulo, que possui 645 municípios, Souza (2010), ao pesquisar a situação do psicólogo inserido na Secretaria da Educação, constatou que, em 133 municípios contatados, apenas 61 municípios contrataram psicólogos para compor o quadro de funcionários das Secretarias de Educação, 58 não contavam com psicólogos e 14 não forneceram informações. Nos 61 municípios com psicólogos contratados, havia 220 profissionais trabalhando apenas na rede municipal. Esse estudo demonstra que ainda há uma pequena parcela de profissionais trabalhando nas escolas públicas.

Os resultados de uma pesquisa conduzida por Cunha e Betini, em 2003, ampliam o entendimento da situação do psicólogo inserido na educação no estado de São Paulo. Oito psicólogas inseridas na rede pública de educação em dois municípios de São Paulo foram entrevistadas. Apenas uma foi contratada para atuar na educação, as demais tinham feito concursos na área da saúde e foram transferidas para a educação. Essa situação indica que o fato de trabalhar com queixas escolares ou mesmo até em escolas não significa que formamos e profissionalizamos o psicólogo para o trabalho na rede educativa.

No estado de Minas Gerais, Soares e Silva (2009), ao investigarem se havia psicólogo na rede municipal de educação, verificaram que, dos 62 municípios mineiros contatados em um conjunto de 853 municípios existentes no estado, 35,48\% deles contavam com psicólogos escolares, totalizando 37 profissionais na rede. No entanto, em uma investigação posterior, ao realizar o mapeamento em 97 cidades ainda no estado, a pesquisa de Silva e Santos (2011) encontrou o psicólogo escolar em 43 municípios ligados à Secretaria da Educação (44\%) e, ao realizar entrevistas com 18 profissionais, constataram que, apesar dos avanços teóricos incorporados nos discursos dos participantes, ainda existe uma dificuldade em adotar uma prática crítica que promova mudanças na rede de ensino. Em três anos, a situação do profissional de Psicologia no estado não mudou substancialmente, apesar de um pequeno acréscimo na porcentagem de municípios com psicólogos para a rede de educação.

Em Rondônia, onde existem 52 municípios, a Secretaria Municipal de Porto Velho possui um total de seis profissionais de Psicologia atuando na área da educação. Ressalta-se que os primeiros concursos públicos para psicólogo escolar ocorreram em 2001 e 2003. Desse período até 2006, havia 97 psicólogos inseridos nas escolas estaduais sendo que, em 2009, esse número se reduziu para 27 em decorrência da baixa remuneração para o trabalho (Tada, Sápia, \& Lima, 2010).

No estado de Santa Catarina, que possui 293 municípios, Tondin, Dedonattie e Bonamigo (2010), ao fazerem um levantamento em 177 municípios, constataram que apenas 27 contavam com psicólogos na educação, sendo que 12 deles possuíam legislação específica para a inserção do psicólogo no quadro funcional da educação, 14 não possuíam essa especificidade e em um município não foi possível obter a informação. Importante destacar que, dos 177 municípios estudados, 74 possuíam psicólogo da Secretaria de Saúde prestando serviço na Secretaria da Educação, um reflexo claro da política vigente na área. Em uma pesquisa posterior, Tondin, Schott, Fiabini e Bonamigo (2011), ao entrevistarem sete profissionais que trabalham na Secretaria da Educação, verificaram uma predominância na Educação Infantil e Fundamental, realizando trabalhos com alunos, pais, professores e funcionários.

No estado do Acre, que possui 22 municípios, Tada (2011) informa, em um levantamento realizado, que apenas no município de Rio Branco existem 11 psicólogos escolares, sendo que 55\% foram contratados como professores e $45 \%$ como psicólogos. De acordo com os resultados encontrados, todos os psicólogos formaram-se em outro estado, a maioria atua na área da Educação Especial e há o predomínio das práticas clínicas.

No estado da Bahia, com 417 municípios, de acordo com os dados levantados por Viegas (2011), foram consultados 372 municípios. Destes, apenas 32 possuíam psicólogo na Secretaria de Educação, destacando que não há na cidade de Salvador. Dos 41 profissionais encontrados, apenas 28 participaram da pesquisa. Em geral, os resultados apontaram que todos fizeram uma especialização, sendo a minoria na área da Educação. Outro dado importante refere-se ao campo da atuação, em que todos indicaram ter como público-alvo a criança e a família, e menos da metade incluiu os educadores. A autora conclui que ainda há o predomínio da modalidade clínica na prática dos profissionais na escola.

No estado do Paraná, com 399 municípios, a pesquisa de Facci, Barroco e Leal (2011), revela que, dos 99 municípios contatados, 56 possuíam psicólogo na rede pública de educação. Dos 39 questionários enviados aos profissionais, apenas 29 foram respondidos, e os resultados apontaram que há o predomínio da atuação na Educação Infantil e Fundamental com alunos, professores e pais. A prática, nesse caso, envolvia prioritariamente uma avaliação psicoeducacional das queixas escolares e formação de professores. As autoras enfatizam que há um avanço na compreensão do papel do psicólogo com relação às queixas escolares, identificando-o para além apenas da aparência do fenômeno e da culpabilização dos estudantes pelas dificuldades.

No Brasil não há uma obrigatoriedade do profissional de Psicologia nas escolas públicas e privadas em âmbito nacional. No entanto, alguns esforços têm sido direcionados à inserção do profissional na rede, como é o caso do Projeto de Lei No 3.688 - C de 2000 que previa, inicialmente, somente a inclusão dos assistentes sociais e que foi ampliado para os profissionais de Psicologia, conforme expresso no Artigo $1^{\circ}$ do $\mathrm{PL}$ :

Art. $1^{\circ}$ O Poder Público deverá assegurar atendimento 
por Psicólogos e Assistentes Sociais a alunos das escolas públicas de educação básica que dele necessitarem.

§ $1^{\circ} \mathrm{O}$ atendimento previsto no caput deste artigo será prestado por Psicólogos vinculados ao Sistema Único de Saúde (SUS) e por Assistentes Sociais vinculados aos serviços públicos de assistência social.

$\S 2^{\circ}$ Os sistemas de ensino, em articulação com os sistemas públicos de saúde e assistência social, deverão prever a atuação de Psicólogos e Assistentes Sociais nos estabelecimentos públicos de educação básica ou o atendimento preferencial nos serviços de saúde e assistência social a alunos das escolas públicas de educação básica, fixando em qualquer caso número de vezes por semana e horários mínimos para esse atendimento.

Nesse Projeto de Lei, a proposta de inserção do psicólogo na educação deve ser prestada por profissionais vinculados à Secretaria de Saúde, o que se caracteriza em um desvio de função, em uma insuficiência na formação para o campo e uma política que mantém a perspectiva e o modelo médico para a profissão. Isto é, a simples transferência do profissional da saúde para a educação conduz a uma intervenção deficitária, dado que a formação inicial do profissional não contempla a educação, e suas práticas se desenvolvem transferindo o modelo médico para dentro da escola.

Essa proposta vai de encontro aos esforços de fortalecimento e qualificação dos profissionais de Psicologia para atuarem no contexto educativo. Para Prilleltenski e Nelson (2002), a manutenção do modelo médico nos contextos educativos se revela como um elemento conservador da Psicologia a serviço da manutenção do status quo, sobretudo no modo de entender e atuar diante dos problemas e da dinâmica da escola. Para os autores, com os quais temos acordo, uma mudança social somente pode acontecer quando a prática profissional e a formação também mudarem. A compreensão da realidade e do cotidiano das escolas públicas, os fundamentos teóricos que sustentam o entendimento dessa realidade e as formas de lidar com ela somente se ampliam e se efetivam se os profissionais estiverem inseridos no campo, devidamente preparados para tal e regulamentados para o exercício profissional.

Um debate sobre a inserção do psicólogo nas Secretarias Municipais e Estaduais de Educação exige, obrigatoriamente, uma discussão sobre a participação ativa desse profissional na construção, aplicação e avaliação das políticas públicas educacionais em nosso país. A prática do psicólogo escolar e educacional deve se situar numa perspectiva crítica e de caráter político, conforme apontam várias pesquisas, como as de Guzzo (2003), Cruces (2006), Oliveira \& Marinho-Araujo (2009) e Guzzo e Mezzalira (2011).

Pensando a respeito disso, o Conselho Federal de Psicologia - CFP, no ano de 2008, realizou vários eventos regionais e nacionais para discutir, coletivamente, as políticas educacionais brasileiras e a inserção e participação dos psicólogos na construção dessas políticas ${ }^{1}$. O CFP apresentou um quadro de atividades desenvolvidas, sob a forma de oficinas ou conversas preparatórias aos seminários regionais. O número dos participantes nos debates promovidos variou de região para região, agregando de 50 (CRP-02 Pernambuco) a 556 psicólogos (CRP-06 - São Paulo). Ao todo, 4.892 profissionais participaram do Ano Temático da Educação do Sistema Conselhos, o que representa ainda uma parte pequena da quantidade de psicólogos inscritos no sistema, um número aproximado de 150 mil profissionais referenciado no texto de Yamamoto (2007).

A partir desses encontros temáticos, foram elaborados relatórios produzidos pelos Conselhos Regionais que foram sistematizados e categorizados pelo Conselho Federal e apresentados no Seminário Nacional do Ano da Educação - Psicologia: Profissão na Construção da Educação para Todos (CFP, 2009). O presente estudo analisou esses relatórios, identificando os problemas e as perspectivas necessárias à inserção do psicólogo na rede pública de ensino e, por consequente, à sua participação nas políticas públicas educacionais brasileiras.

\section{Método}

Utilizamos como fonte de informações para análise neste trabalho os relatórios produzidos pelos Conselhos Regionais e apresentados no Seminário Nacional do Ano da Educação - Psicologia: Profissão na Construção da Educação para Todos, que foi realizado no início de 2009, na sede do Conselho Federal de Psicologia em Brasília. É preciso informar que o Conselho Federal de Psicologia - CFP sistematizou e categorizou as contribuições dos eventos regionais a respeito de cada eixo temático de discussão ${ }^{2}$ em um material compilado pelo CFP.

$1 \quad$ Para subsidiar essas discussões, foram elaborados quatro textos geradores que contemplam os conteúdos dos eixos temáticos definidos como norteadores do debate. Os textos foram intitulados da seguinte maneira: 1) Psicologia, políticas públicas intersetoriais e educação inclusiva (de autoria de Cristina Maria Carvalho Delou); 2) Políticas educacionais: legislação, formação profissional e participação democrática (autoras: Marilene Proença Rebello de Souza e Marisa Lopes da Rocha); 3) Psicologia e instituições escolares e educacionais (autora: Raquel Souza Lobo Guzzo); 4) Psicologia no ensino médio (autoras: Ângela Fátima Soligo e Roberta Gurgel Azzi).

2 Categorias de cada eixo temático elaborado pelo CFP: Eixo 1 - Psicologia, políticas públicas intersetoriais e educação inclusiva: Formação do profissional; Prática profissional; Papel do sistema conselhos / mobilização da categoria; Políticas públicas: inserção do psicólogo nas políticas públicas intersetoriais e nos documentos normativos, políticas no campo da educação, inserção do psicólogo nos órgãos públicos; Conceituação; Campo da educação. Eixo 2 - Políticas educacionais: legislação, formação profissional e participação democrática: Formação; Participação democrática; Legislação; Outros temas. Eixo 3 - Psicologia e instituições escolares e educacionais: Questionamentos dos conselhos regionais de psicologia sobre Atuação do psicólogo no campo da educação; Inserção do psicólogo no campo da educação; 
Para o presente trabalho, o procedimento de análise consistiu na releitura detalhada das categorias amplas de cada eixo temático apresentadas pelo CFP com o objetivo de identificar dois aspectos: as situações e/ou elementos que poderiam estar impedindo a inserção do psicólogo na rede pública de ensino e as perspectivas apresentadas como norteadoras para a inserção desse profissional nas políticas públicas educacionais.

Assim, a partir da leitura das categorias apresentadas em cada eixo temático pelo CFP, foram eleitos trechos específicos que correspondiam ao objetivo deste trabalho. Esses trechos se constituíram em unidades de sentido, permitindo uma reorganização da participação dos conselhos regionais na discussão desse tema, conforme o modelo construtivo-interpretativo elaborado por González-Rey (2002).

\section{Resultados e Discussão}

O processo de construção de categorias como procedimento metodológico representa a organização de esforços com finalidade explicativa. Assim, nesta seção, serão apresentadas as categorias que foram construídas a partir das unidades de sentido, isto é, aquelas que representam o resultado do nosso processo de análise. Elas cumprem a tarefa de explicar quais são os elementos que impedem a inserção do psicólogo na rede pública de ensino e quais são as possibilidades de ações para sua inserção nos espaços de deliberação das políticas públicas educacionais.

Estas categorias devem ser observadas como resultado do processo de extração de sentidos e consideradas a partir das reflexões que suscitam. Deste modo, elas não representam dados estanques, mas indicam uma possível elaboração analítica cuja finalidade última é explicar porque os psicólogos não têm ocupado todas as secretarias de educação no Brasil.

As grandes categorias construídas são as seguintes: Psicologia Escolar e Educacional: formação e pesquisa em políticas públicas; Psicólogo escolar e educacional: inserção e participação nas políticas públicas educacionais; e Inserção do psicólogo no contexto público educacional: dilemas e perspectivas.

\section{Psicologia Escolar e Educacional: formação e pesquisa em políticas públicas}

\footnotetext{
Proposições sobre a atuação do psicólogo no campo da educação - produção de conhecimento, formação e lugar do sistema conselhos; Considerações finais. Eixo 4 - Psicologia no Ensino Médio: Psicologia como disciplina no ensino médio - história, finalidades, defesas e críticas, campanha; Argumentos favoráveis à inserção da psicologia no ensino médio; Enfoques metodológicos: disciplinaridade, interdisciplinaridade ou transversalidade?; Conteúdos da disciplina de psicologia no ensino médio; Psicologia escolar e professor de psicologia; Formação do professor de psicologia; Mercado de trabalho e o professor de psicologia.
}

Esta categoria aglutina os trechos contidos no relatório compilado pelo CFP que possuíam relatos dos profissionais reivindicando a inclusão das políticas públicas no currículo de formação do psicólogo. Observe os trechos a seguir:

"Inserir na formação do psicólogo as políticas públicas e a história da educação" (CRP 14).

"Apontar para uma reformulação dos currículos dos cursos de psicologia de forma a contemplar temáticas relativas às políticas publicas e, a partir daí, buscar o fortalecimento das políticas educacionais" (CRP 13).

"Elaboração das diretrizes curriculares para o curso de graduação em psicologia: compreensão crítica dos fenômenos sociais, econômicos, culturais e políticos do país, fundamentais ao exercício da cidadania e da profissão" (CRP 01).

\begin{abstract}
"As políticas públicas e a legislação pertinentes à educação devem constituir temática nas grades curriculares dos cursos de graduação em Psicologia, fortalecendo os currículos e a formação profissional" (CRP 14).
\end{abstract}

A pesquisa de Cunha e Betini (2003) revelou o impacto da formação profissional cindida de suas implicações políticas na prática do psicólogo escolar e educacional. Nesse estudo, os psicólogos da Secretaria de Educação verbalizaram que não foram preparados adequadamente para atuar na realidade social porque não tiveram conteúdos que discutissem as políticas públicas de educação, bem como não foram preparados para desenvolver trabalhos voltados a uma perspectiva de prevenção. Essa urgência de estimular a consciência política dos alunos de Psicologia foi observada nos encontros:

"Proporcionar aos alunos de Psicologia uma visão crítica política" (CRP 15).

"Discutiu-se a formação do psicólogo, que precisa incluir uma formação crítica, política, e não apenas uma ação que enfatize a saúde e uma ideologia 'psicologizante'" (CRP 04).

"Fomentar a formação política nos cursos de graduação de Psicologia" (CRP 17).

Percebeu-se, ainda, por meio das análises dos relatos dos profissionais, a urgência em desenvolver práticas de estágios voltados para a participação efetiva dos alunos nas políticas públicas.

"Falta de prática e estágios na graduação voltados às políticas públicas e à educação em geral" (CRP 08).

"Estimular junto ao MEC e as instituições de ensino superior a articulação do estágio de psicologia escolar com as políticas 
educacionais, em instituições escolares e educacionais, possibilitando uma atuação voltada para o conhecimento" (CRP 11).

"As práticas críticas devem fomentar a ação dos psicólogos na educação, de modo que as demandas reflitam as necessidades sociais da população envolvida (as universidades, assim como os psicólogos, devem produzir práticas reflexivas e fomentar isso com o público. Essa prática reflexiva deve estar conectada ao social e as suas demandas)" (CRP 14).

Refletindo sobre esses relatos apresentados, Belluzzo e Cunha (2003) destacam a importância de os cursos de formação possibilitarem aos alunos de Psicologia experiências de estágios que permitem uma compreensão do contexto social no qual irão trabalhar. Referindo-se ainda a esse assunto, Martínez (2007) faz uma crítica à formação inicial do psicólogo, explicando que esta precisa estar orientada para a prática profissional, de modo a não fragmentá-la da realidade.

Outras questões trazidas pelos psicólogos durante os encontros foram com relação à produção e à divulgação de conhecimentos direcionados à situação das políticas públicas educacionais e à inserção do psicólogo escolar / educacional na rede pública de ensino:

"Incentivar pesquisas, no âmbito acadêmico, na área de políticas públicas de Educação" (CRP 17).

"Estimular junto ao MEC e às instituições de ensino superior a efetivação, através da pesquisa e extensão, de uma produção de conhecimento científico voltada para as políticas educacionais, possibilitando ao futuro profissional uma formação ampla e crítica da realidade em que está inserido e o seu comprometimento com a transformação social" (CRP 11).

"Criar comissões de estudo e assessoramento articulada às entidades educacionais para investigar, nos diferentes estados e municípios, de que forma tem sido criado o cargo de psicólogo na rede pública de ensino" (CRP 11).

"Promover espaços de discussão coletiva entre psicólogos e demais profissionais que atuam na Educação e em setores da sociedade, objetivando a construção e divulgação de referências técnicas e políticas para a atuação do psicólogo no campo escolar/educacional. Tais atividades visam à qualificação do psicólogo técnica e politicamente, para melhor compreender a complexidade do sistema educacional atual, buscando o aperfeiçoamento da atuação profissional" (CRP 13).

"Difundir, para além dos limites acadêmicos, as práticas do psicólogo na Educação que considerem e se comprometam com os fatores sociais" (CRP 06).
Essa necessidade está referendada no trabalho de Medeiros e Aquino (2011). Elas afirmam que é relevante desenvolver pesquisas em torno da formação e atuação do psicólogo escolar, principalmente com relação ao campo de trabalho, para conhecer melhor a realidade e as formas de atuação desse profissional.

A questão da qualidade da formação em Psicologia é, sem dúvida, um ponto crucial para a discussão sobre o tipo de prática profissional que tem sido desenvolvida nos contextos educativos. Gatti (2009) acentua que a melhoria dos indicadores educacionais e dos desempenhos escolares tem sido um grande desafio para o país. Todavia, essa expansão não é direcionada por avanços qualitativos e, nesse sentido, os administradores públicos da educação escolar e os demais trabalhadores da educação, em diferentes níveis e modalidades, deveriam se envolver com a produção de políticas e ações coerentes com as demandas do país. O psicólogo que orienta seus esforços para o campo educacional é, portanto, um trabalhador da educação e deve estar implicado nessa construção.

\section{Psicólogo escolar e educacional: inserção e participação nas políticas públicas educacionais}

Nesta categoria foram consideradas as recomendações existentes no relatório compilado pelo CFP quanto à atuação do psicólogo nos contextos políticos e educativos. O que se vem percebendo, de acordo com os debates, é a necessidade de o psicólogo desenvolver estratégias de intervenções que possibilitem a inserção do psicólogo nos espaços públicos que discutem as políticas educacionais brasileiras. Dentre as estratégias consideradas importantes pelos profissionais, podemos citar os seguintes trechos:

"Incentivar a participação dos psicólogos em espaços de deliberação de políticas relacionadas às populações historicamente excluídas dos/nos sistemas educacionais, pautada na perspectiva de Educação pública e de qualidade para todos como a inserção do psicólogo educacional em equipes interdisciplinares" (CRP 11).

"Os psicólogos na Educação necessitam se organizar enquanto categoria e reivindicar junto aos órgãos gestores o reconhecimento e a valorização profissional" (CRP 02).

"A importância de o psicólogo participar de discussões sobre o sistema educacional (duração hora aula, número de alunos por sala, método generalizado de ensino) visando sua reformulação" (CRP 06).

"É necessário estabelecer contato e a realização de parcerias com órgãos governamentais para esclarecimentos de públicos diversos como gestores, profissionais de outras áreas. Essas parceiras devem, ainda, ter como objetivo o estabelecimento de políticas públicas que envolvam a Psicologia" (CRP 01). 
"Promover, junto aos gestores públicos, discussões acerca da importância do profissional psicólogo atuando junto às políticas públicas de Educação" (CRP 17).

"Garantir a presença do psicólogo nos sistemas de ensino, através de elaboração de projetos de lei junto a parlamentares municipais, estaduais, federais" (CRP 09).

"Promover fóruns de discussões com a categoria e entidades do executivo, legislativo e judiciário para tratar da inserção do psicólogo escolar e educacional na rede pública" (CRP 11).

Nos relatos dos profissionais, podemos destacar, de um modo geral, como uma das atuações do psicólogo escolar e educacional a participação ativa nos espaços públicos, como fóruns e audiências, com o objetivo de auxiliar na construção das políticas públicas, bem como reivindicar a sua inserção no sistema público de educação.

Essa perspectiva de atuação apontada pelos profissionais se faz coerente, de alguma forma, com as pesquisas ligadas a essa temática. Patto (2005), ao problematizar a produção de saber sobre as políticas educacionais e da escola, especialmente nos cursos de pós-graduação, afirma que sua contribuição é vasta e coerente com as demandas fundamentais da escola pública. No entanto, a autora salienta que, para atingir as mudanças que desejamos, essas reflexões precisam se materializar em movimentos sociais e reivindicatórios.

A elaboração desta categoria resgata um aspecto essencial deste "quefazer" social ao salientar a importância de que o psicólogo participe dos espaços de deliberação e construção das políticas educacionais. Isso porque as reflexões, sem o substrato da prática, tornam-se vazias e descoladas das demandas da realidade.

\section{Inserção do psicólogo no contexto público educacional: dilemas e perspectivas}

Esta categoria refere-se a todos os relatos trazidos nos debates realizados nos conselhos regionais e registrados no relatório que discutem a situação dos concursos públicos no país e dão sugestões de melhorias. De acordo com os conselhos regionais, os concursos públicos em alguns estados e municípios precisam de uma atenção no que diz respeito à indefinição da área nos concursos, além do número de psicólogos contratados não ter uma relação com a população atendida.

"Os concursos públicos para psicólogos não definem a área de atuação. E quando definem não garantem que essa área será mantida. Isso gera situações em que um psicólogo contratado para a área da saúde é 'emprestado' para a educação e vice-versa" (CRP 08).

"Não há um parâmetro da relação número de psicólogo/ número da população atendida que favoreça a contratação de um número mínimo de profissionais para que o trabalho seja realizado" (CRP 08).

A indefinição nos editais do cargo a ser ocupado pelo psicólogo tem se configurado como um entrave para uma ação contextualizada e crítica desse profissional no sistema público de ensino. Isso porque, conforme é retratado na pesquisa de Cunha e Betini (2003), os psicólogos vinculados à Secretaria de Saúde, ao serem deslocados para a Secretaria da Educação, tendem a atuar de uma forma remediativa e individualizada, em virtude da grande demanda de encaminhamentos e da concepção limitada com relação às dificuldades de aprendizagem. Por isso, nos relatos dos profissionais, reivindica-se a definição do cargo do psicólogo nos editais e a contratação apenas de profissionais especializados ou com experiência na área:

"Exigência nos concursos públicos de comprovação de formação ou experiência na área de contratação" (CRP 08).

"Exigir nos concursos públicos as capacitações necessárias, especializadas para a função, bem como garantir a formação" (CRP 14).

"Em alguns estados da jurisdição do CRP, os critérios utilizados para a seleção de pessoal para trabalhar com Psicologia Escolar no serviço público ainda é baseado no insucesso e nos problemas clínicos" (CRP 01).

Surge também, nos relatos dos profissionais, a necessidade de discutir as bibliografias sugeridas nos concursos:

"É preciso discutir as pautas/bibliografias dos concursos que envolvem a atuação de psicólogos em políticas públicas (Ex: provas exigem uma formação clínica e conhecimentos psicanalíticos e a atuação profissional necessita ser política, institucional, crítica, exige outros conhecimentos)" (CRP 04).

Além disso, segundo aponta Tada, Sápia e Lima (2010), há outro agravante com relação aos concursos públicos para o psicólogo escolar nas secretarias de educação, no caso, a desvalorização do seu serviço expresso nos baixos salários. Essa realidade tem contribuído para o não preenchimento de todas as vagas disponíveis para esse profissional e mesmo a desistência de profissionais, como anteriormente citado.

Diante disso, depreende-se que essas críticas são fundamentais para entendermos como vem se configurando a situação dos concursos públicos para os psicólogos em nosso país. Em geral, os referenciais teóricos contemplados pelos editais estão distantes da realidade de trabalho, os salários são baixos, e o governo, por não entender a ação do psicólogo, designa outros profissionais para assumir seu cargo. Essa questão pode ser observada nas denúncias a seguir:

"Os órgãos públicos não reconhecem e existe a 
descaracterização do exercício profissional do psicólogo na educação. Isso é exemplificado com as poucas oportunidades nos concursos públicos ou no desvio de função muito frequente nas instituições" (CRP 02).

"Alguns espaços institucionais contratam pedagogos que fizeram especialização em psicopedagogia e, quando questionadas sobre o porquê da não contratação do psicólogo escolar, respondem que o psicopedagogo atende às necessidades, não havendo, portanto, motivação para ter o psicólogo escolar / educacional em seus quadros" (CRP 02).

Enfim, essa situação vem se configurando como um grande empecilho para a inserção de um profissional qualificado e preparado no contexto público de educação. Nesse sentido, a inserção do psicólogo na rede poderia ser respaldada por uma fiscalização rigorosa dos editais para essa área pelo sistema conselho e universidades, garantindo que os concursos respeitem os conteúdos teóricos e as práticas profissionais referenciados para esse campo de trabalho.

\section{Considerações Finais}

Os resultados encontrados nesta pesquisa revelaram alguns elementos que poderiam estar impedindo a entrada do psicólogo na rede pública de educação, bem como possibilitaram uma reflexão sobre alguns encaminhamentos direcionados para o enfrentamento dessa situação.

A formação do psicólogo desprovida de discussões políticas e de práticas direcionadas a sua participação na construção da profissão tem se configurado como um empecilho e por isso torna-se de fundamental importância que haja uma mudança na grade curricular dos cursos de graduação, com vistas à contemplação dessas questões.

A inserção do profissional de Psicologia Escolar e Educacional nos espaços públicos, como fóruns e audiências que discutem políticas públicas educacionais, torna-se imprescindível para efetivar a sua entrada no contexto educativo. Ressalta-se que a luta pela sua admissão como funcionário da escola perpassa, obrigatoriamente, pela exigência de definições de sua atuação nos editais, evitando a alocação de psicólogos de outras secretarias para agir na escola. Além disso, torna-se necessário ter um olhar crítico na escolha dos referenciais teóricos que serão cobrados nos concursos. Isso porque o estudo de teorias que não contemplam uma visão contextualizada dos alunos fortalece uma prática clínica e remediativa do psicólogo no contexto escolar.

Em geral, esta pesquisa contribui para uma breve reflexão sobre como vem se configurando a entrada do psicólogo nas políticas públicas educacionais no nosso país, mas não esgota todos os fatores que interferem em sua inserção no contexto educativo. E, com isso, aponta caminhos para estudos organizados para um maior impacto na área, sejam voltados para a formação básica dos profissionais de Psicologia, sejam para fornecer subsídios aos fóruns e espaços formuladores de políticas públicas para a área e, por fim, para que revelem de modo coeso e organizado o que tem sido, de fato, a produção e o avanço da área no país.

Se, hoje, falar da Psicologia Escolar no Brasil é dizer de algo que ainda não se concretizou na prática para além de algumas experiências pioneiras e não universalizadas, espera-se que, em um futuro breve, os profissionais que escolham se envolver com o desenvolvimento de crianças e adolescentes em espaços educativos vejam nessa direção uma proposta concreta de trabalho e de mudança da realidade.

\section{Referências:}

Carvalho, T. O., \& Marinho-Araujo, C. M. (2009). Psicologia escolar no Brasil e no Maranhão: percursos históricos e tendências atuais. Psicologia Escolar e Educacional, 13(1), 65-73.

Conselho Federal de Psicologia. (2008). Ano da Psicologia na Educação - Textos Geradores. Brasília, DF.

Conselho Federal de Psicologia. (2009). Seminário Nacional do Ano da Educação - Psicologia : Profissão na Construção da Educação para Todos. Brasília, DF.

Cruces, A. V. V. (2006). Psicologia e Educação: nossa história e nossa realidade. Em S. F. C. Almeida (Org.), Psicologia Escolar - ética e competência na formação profissional. Campinas, SP: Alínea.

Cunha, B. B. B., \& Betini, G. (2003). Psicologia e educação no contexto das secretarias municipais. Psicologia Ciência e Profissão, 23(3), 42-49.

Facci, M. G. D., Barroco, S. M. S., \& Leal, Z. F. R. G. (2011). Atuação dos psicólogos escolares do Paraná: em defesa da socialização dos conhecimentos. [Resumo]. Em Associação Brasileira de Psicologia Escolar e Educacional - ABRAPEE, $X$ Congresso Nacional de Psicologia Escolar e Educacional (p. 176). Maringá, PR: CONPE.

Gatti, B. A. (2009). Políticas, ações educacionais e desempenho escolar. Em M. G. Arroyo \&A. Abramowicz (Orgs.), A reconfiguração da escola: entre a negação e a afirmação de direitos. (pp. 35-48). Campinas, SP: Papirus.

Guedes, A. C. M., Aguiar, K. F., Rocha, M. L., \& Cunha, V. V. (2009). Psicólogo na escola pública do Rio de Janeiro: desafios na construção de outros possíveis [Resumo]. Em Associação Brasileira de Psicologia Social, XV Congresso Nacional de Psicologia Social. Maceió, AL: ABRAPSO.

González-Rey, F. (2002). Pesquisa qualitativa em Psicologia: caminhos e desafios. São Paulo: Pioneira Thomson. 
Guzzo, R. S. L. (2003). Educação para a liberdade, Psicologia da libertação e Psicologia Escolar: uma práxis para a realidade. Em S. F. Almeida (Org.), Psicologia escolar: ética e competência na formação e atuação profissional (pp. 169-178). Campinas, SP: Alínea.

Guzzo, R. S. L., Martínez, A. M., \& Campos, H. (2006). School Psychology in Brazil. Em S. Jimerson; T. Oakland \& P. Farrell, The handbook of international school psychology. United States of American: Sage Publications.

Guzzo, R. S. L., \& Mezzalira, A. S. C. (2011). 2008 - Ano da Educação para os psicólogos: encaminhamentos e próximos passos. Em R. S. L. Guzzo \& C. M. Marinho-Araujo (Org.), Psicologia Escolar: identificando e superando barreiras. Campinas, SP: Átomo \& Alínea.

Marinho-Araujo, C. M. (2010). Psicologia Escolar: pesquisa e intervenção. Em: C. M. Marinho-Araujo (Org.), Em Aberto (pp. 17-38). Brasília: Instituto Nacional de Estudos e Pesquisas Educacionais Anísio Teixeira.

Marinho-Araujo, C. M., Neves, M. M. B. J., Penna-Moreira, P. C. B., \& Barbosa, R. M. (2011). Psicologia Escolar no Distrito Federal: história e compromisso com políticas públicas. Em R. S. L. Guzzo \& C. M. Marinho-Araujo (Org.), Psicologia Escolar: identificando e superando barreiras. Campinas, SP: Átomo \& Alínea.

Martínez, A. M. (2007). O psicólogo escolar e os processos de implantação de políticas públicas. Em H. Campos (Org.), Formação em Psicologia escolar: realidades e perspectivas (pp. 109-133). Campinas, SP: Alínea.

Medeiros, L. G., \& Aquino, F. S. B. (2011). Atuação do psicólogo escolar na rede pública de ensino: concepções e práticas. Psicologia Argumento, 29(65), 227-236.

Oliveira, C. B. E., \& Marinho-Araujo, C. M. (2009). Psicologia Escolar: cenários atuais. Estudos e Pesquisas em Psicologia, 9(3), 648663.

Patto, M. H. S. (1997). Introdução à Psicologia Escolar. São Paulo: Casa do Psicólogo.

Patto, M. H. S. (2004). Ciência e política na primeira república: origens da Psicologia Escolar. Mnemosine, 1, 203-225.

Patto, M. H. S. (2005). Democratização do ensino e políticas públicas: desafios para a pesquisa. Em M. H. S. Patto (Org.), Exercícios de indignação (pp. 57-67). São Paulo: Casa do Psicólogo.

Pandolfi, C. C., Ota, A. E., Strini, G., Buzolin, I. V. B. O., Martins, J. B.,
\& Casagrande, L. M. (1999). A inserção do psicólogo escolar na rede municipal de Londrina - PR. Psicologia Ciência e Profissão, 19(2), 30-41.

Prilleltenski, I., \& Nelson, G. (2002). Doing Psychology Critically Making a Difference in Diverse Settings. New York: Palgrave MacMillan.

Rossetti, C. B., Silva, C. A., Batista, G. L., Stein, L. A., \& Hulle, L. O. (2004). Panorama da psicologia escolar na cidade de Vitória: um estudo exploratório. Paidéia, 14(28), 191-195.

Silva, S. M. C., \& Santos, A. A. C. (2011). Um estudo sobre a atuação do psicólogo na rede pública de Educação de Minas Gerais. [Resumo]. Em Associação Brasileira de Psicologia Escolar e Educacional - ABRAPEE, $X$ Congresso Nacional de Psicologia Escolar e Educacional (p. 176). Maringá, PR: CONPE.

Soares, S. S., \& Silva, S. M. C. (2009). A atuação do psicólogo na rede pública de educação frente a demanda escolar: concepções, práticas e inovações [Resumo]. Em IX Encontro Interno \& XIII Seminário de Iniciação Científica da Universidade Federal de Uberlândia.

Souza, M. P. R. (2010). A atuação do psicólogo na rede pública de educação: concepções, práticas e desafios. Tese de livredocência, Universidade de São Paulo, São Paulo.

Tada, I. N. C. (2011). A atuação do psicólogo escolar no Acre. [Resumo]. Em Associação Brasileira de Psicologia Escolar e Educacional - ABRAPEE, $X$ Congresso Nacional de Psicologia Escolar e Educacional (p. 101). Maringá, PR: CONPE.

Tada, I. N. C., Sápia, I. P., \& Lima, V. A. A. (2010). Psicologia Escolar em Rondônia: formação e prática. Psicologia Escolar e Educacional, 14(2), 333-340.

Tondin, C. F., Dedonattie, D., \& Bonamigo, I. S. (2010). Psicologia escolar na rede pública de educação dos municípios de Santa Catarina. Psicologia Escolar e Educacional, 14(1), 65-72.

Tondin, C. F., Schott, D. F., \& Bonamigo, I. S. (2011). Psicologia Escolar na rede pública de Educação de Santa Catarina. [Resumo]. Em Associação Brasileira de Psicologia Escolar e Educacional - ABRAPEE, $X$ Congresso Nacional de Psicologia Escolar e Educacional (p.49). Maringá, PR: CONPE.

Viegas, L. S. (2011) A atuação do psicólogo na rede pública baiana de Educação. [Resumo]. Em Associação Brasileira de Psicologia Escolar e Educacional - ABRAPEE, $X$ Congresso Nacional de Psicologia Escolar e Educacional (p. 49). Maringá, PR: CONPE.

Yamamoto, O. H. (2007). Políticas sociais, "terceiro setor" e "compromisso social": perspectivas e limites do trabalho do psicólogo. Psicologia \& Sociedade, 19(1), 30-37 
Recebido em: 30/11/2011

Reformulado em: 24/01/2012

Aprovado em: 03/02/2012

Sobre as autoras

Raquel Sousa Lobo Guzzo

Psicóloga, doutora e professora titular do curso de pós-graduação em Psicologia da PUC-Campinas.

Adinete Sousa da Costa Mezzalira (adinetecosta@hotmail.com)

Psicóloga e doutora em Psicologia como Profissão e Ciência pela PUC - Campinas.

\section{Ana Paula Gomes Moreira}

Psicóloga e doutoranda do curso de pós-graduação em Psicologia pela PUC-Campinas.

Endereço para correspondência: Av. Princesa D'Oeste, 440, apt 23. Bairro: Jardim Paraíso. CEP: 13100-040 Campinas-SP. 